\title{
Erratum: Congenital Chikungunya Virus Infection after an Outbreak in Salvador, Bahia, Brazil
}

\author{
Priscila Pinheiro Ribeiro Lyra, MD ${ }^{1}$ Gúbio Soares Campos, $\mathrm{PhD}^{2} \quad$ Igor Dórea Bandeira ${ }^{1}$ \\ Silvia Ines Sardi, PhD ${ }^{2}$ Lilian Ferreira de Moura Costa, PhD $^{2}$ Flávia Rocha Santos ${ }^{2}$ \\ Carlos Alexandre Santos Ribeiro, $\mathrm{MD}^{1}$ Alena Maria Barreto Jardim, MD ${ }^{1}$ \\ Ana Cecília Travassos Santiago, MD ${ }^{1}$ Patrícia Ribeiro de Oliveira, MD ${ }^{1} \quad$ Lícia Maria Oliveira Moreira, MD ${ }^{1}$ \\ ${ }^{1}$ Department of Pediatrics, Climério de Oliveira Maternity, \\ Federal University of Bahia School of Medicine, Bahia, Brazil \\ ${ }^{2}$ Laboratory of Virology, Health Science Institute, Federal University of \\ Bahia, Bahia, Brazil \\ Address for correspondence Priscila Pinheiro Ribeiro Lyra, MD, \\ Department of Pediatrics, Universidade Federal da Bahia, Avenue \\ Reitor Miguel Calmon S/N, Canela Salvador-BA, Salvador, Bahia 40110- \\ 060, Brazil (e-mail: priscilalyra@yahoo.com).
}

Am J Perinatol Rep 2016;6:e324.

\section{ERRATUM}

It has been brought to our attention that the name of Patrícia Ribeiro de Oliveira appeared incorrectly in the above article published online in American Journal of Perinatology Reports (volume 6, issue 3, pp. e299-e300; DOI: 10.1055/s-0036-1587323). The author name is now correctly listed as Patrícia Ribeiro de Oliveira in the above author byline. 